\title{
Are the Emerging Capital Markets Weak Form Efficient? - Evidence from the Model of the Dhaka Stock Exchange
}

\author{
Muhammad Raquib*, Khairul Alom \\ School of Business Studies, Southeast University, Bangladesh
}

Copyright $@ 2015$ Horizon Research Publishing All rights reserved.

\begin{abstract}
Efficient Market Hypothesis (EMH) has attracted a considerable number of studies in empirical finance, particularly in determining the market efficiency of an emerging financial market that is Dhaka Stock Exchange (DSE). Conflicting and inconclusive outcomes have been generated by various existing studies in EMH. In addition, efficiency tests in the emerging financial markets are rarely definitive in reaching a conclusion about the issue. This paper recommend a paradigm of non-parametric tests of market efficiency for an emerging stock market, that is DSE, consisting of non-parametric test which is autocorrelation function tests (ACF), to establish a more definitive conclusion about EMH in emerging financial markets. The result of this research using Dhaka Stock Exchange General Index (DGEN) demonstrates that a positive autocorrelation on Dhaka Stock Exchange returns exists particularly in the period of 2001-2013 and DSE doesn't hold weak form of efficiency and not following the Random walk model. The inefficiency of the Dhaka Stock Exchange follows on from the violation of the necessary conditions for an efficient market with a developed financial system and also implies financial markets and institutional imperfections.
\end{abstract}

Keywords Efficient Market Hypothesis, Weak-form Market Efficiency, DSE, SEC, Random Walk, Emerging Financial Market

\section{Introduction}

The most divisive issue in finance is possibly whether the financial market is efficient in allocating or using economic resources and information or not. Other financial theory issues such as volatility, predictability, speculation and anomalies are also related to the efficiency issue and are all interdependent (Islam and Oh 2003[1]; Mills 1999[2]; Cuthbertson 1996[3]), and empirical evidence provided by existing numerous tests of these issues (see Bollerslev and Hodrick (1999)[4],Pesaran and Wickens (1999)[5]) is also used in supporting or rejecting efficiency in the financial market. The limitation of the existing empirical tests of the efficiency issue in the financial market (Efficient Market Hypothesis (EMH)) has generated contradictory and questionable outcomes. Efficiency tests in the emerging financial markets are rarely definitive and helpful in reaching a conclusion about the issue.

The major challenges to EMH are mainly in the following forms: empirical tests for EMH show no evidence in favour of EMH, the existence of the limitations of the statistical and mathematical models for EMH, the evidence of the excess volatility mean reversion predictability, the existence of bubbles, and non-linear complex dynamics and turmoil in the stock market. EMH has two dual aspects of the rational expectation hypothesis and the risk-neutral behavior of investing agents. The tests of EMH relate to the issues of predictability, anomaly, seasonality, volatility and the existence of bubbles. Studies of all these issues enable an analyst to draw a conclusion about the efficiency of a financial market of a country.

In the above context, our subject of study is the case of the Dhaka Stock Exchange (DSE) - its recent booming, in fact, at the time of recession when the developed countries capital market (NYSE, LSE, AMEX) and also some of the western emerging capital market had declining trend. In case of DSE we did not observe any such trend and according to the evidence of market indices and different companies' fund collection through capital market as well the size of the DSE capitalization, the market grew day by day. Then there started the continual trend of busts and declines with occasional rises in between.

In this paper our objective is to use autocorrelation function test (ACF) for non-parametric testing of market efficiency; and to try to come to some understanding of efficient market hypothesis in relation to emerging financial markets. The non-parametric autocorrelation test being pursued in this study are targeting consistent statistical characteristics of the price and returns profile, using few inter-linkages with a specific model of asset pricing. If the stock exchange of Dhaka is efficient, the stock prices would correctly and fully reflect all relevant information and hence, no arbitrage opportunities would exist. Thus in this type of 
test, the rejection of the null hypothesis would reject market efficiency that is weak form efficient market hypothesis (WEMH) for the Dhaka stock exchange. The implication of efficiency, in its broadest sense, is that stock prices always reflect their intrinsic worth and can be taken at their face value.

\section{Review of Literature}

\subsection{Market Efficiency Hypothesis}

"An efficient capital market is a market that is efficient in processing information. In an efficient market, prices 'fully reflect' available information" (Fama 1976, p. 133[6]). In the broadest terms of EMH, there are three types of market efficiency. Firstly, in weak form efficiency, the information set is that the market index reflects only the history of prices or returns themselves. Secondly, in semi-strong form efficiency, the information set includes most information known to all market participants. Finally, in strong form efficiency, the information set includes all information known to any market participant.

In the 1960 s and early 1970 s, the controversy focused on the extent to which successive changes in prices of the stocks were independent of each other or whether stock prices followed a random walk. The early tests to answer this question were conducted by Fama (1965)[7] and Samuelson (1965[8]), in which they concluded that most of the evidence seems to have been consistent with the efficient market hypothesis (EMH). Stock prices followed a random walk model and the predictable variations in equity returns, if any, were found to be statistically insignificant. Other studies in the US with similar findings included those of Sharpe (1966)[9], Friend et al. (1970)[10], and Williamson (1972)[11].

Throughout the 1980s, EMH has provided the theoretical basis for much of the research, and most empirical studies during these years focused on predicting prices from historical data, while also attempting to produce forecasts based on variables such as $\mathrm{P} / \mathrm{E}$ ratios (Campbell and Shiller 1987)[12], dividend yield (Fama and French 1989)[13], term structure variables (Harvey 1991)[14], and announcement of various events, i.e. earnings, stock splits, capital expenditure, divestitures, and takeovers (Jensen and Ruback 1983[15]; McConnell and Muscarella 1985[16]; Kettel 2001[17]).

The issue of EMH in relation to stock prices is fundamental for an investigation of the characteristics of the Dhaka stock exchange. The initiator was Alam et al. (1999)[18]. They examined the weak form efficiency of DSE for the period 1986 to 1995 based on the monthly stock price indices. Applying variance ratio test, they revealed that the DSE followed random walk model and the DSE was weak form efficient.

Hassan, Islam and Basher (2000)[19] examined the weak form efficiency in DSE for the period September 1986 November 1999 . They found that the equity return of the
DSE were the positive skewness of 0.11 and 22.93, excess of kurtosis of 49.66 and 992.65 and the deviation from the normality. They also revealed that there was a significant negative serial correlation $(-0.07)$ which implied that the DSE market was not weak form efficient. They further found that there were a significant relationship between the conditional volatility and the stock returns. Mobarek and Keasey (2002)[20] investigated to test weak form efficiency based on the daily price indices of all listed DSE securities for the period 1988 to 1997 . The sample covered 2638 daily observations. They used various tests including Auto-correlation test, Auto-regression and run tests. They concluded that the significant autocorrelation co-efficient at different lags which did not support the weak form efficiency or random walk model of DSE market.

\subsection{Formal Definition of the Concept}

Before we examine the efficiency issues of DSE, we need to revisit the definition of EMH. The EMH is a statement about: (1) the theory that stock prices reflect the true value of stocks; (2) the absence of arbitrage opportunities in an economy populated by rational, profit-maximizing agents; and (3) the hypothesis that market prices always fully reflect available information (Fama 1970)[21]. In Jensen (1978)[22], an efficient market is defined with respect to an information set $\Phi_{t}$ if it is impossible to earn economic profits by trading on the basis of $\Phi_{t}$. Fama (1970)[20] presented a general notation describing how investors generate price expectations for stocks. This could be explained as (Cuthbertson 1996)[3]:

$$
E\left(p_{j, t+1} \mid \Phi_{t}\right)=\left[1+E\left(r_{j, t+1} \mid \Phi_{t}\right)\right] p_{j t}
$$

where $E$ is the expected value operator, $p_{j, t+1}$ is the price of security $j$ at time $t+1, r_{j, t+1}$ is the return on security $j$ during period $t+1$, and $\Phi_{t}$ is the set of information available to investors at time $t$.

The left-hand side of the formula $E\left(p_{j, t+1} \mid \Phi_{t}\right)$ denotes the expected end-of-period price on stock $j$, given the information available at the beginning of the period $\Phi_{t}$. On the right-hand side, $1+E\left(r_{j, t+1} \mid \Phi_{t}\right)$ denotes the expected return over the forthcoming time period of stocks having the same amount of risk as stock $j$.

Under the efficient market hypothesis (EMH), investors cannot earn abnormal profits on the available information set $\Phi_{t}$ other than by chance. The level of over value or under value of a particular stock is defined as:

$$
x_{j, t+1}=p_{j, t+1}-E\left(p_{j, t+1} \mid \Phi_{t}\right)
$$

where $x_{j, t+1}$ indicates the extent to which the actual price for security $j$ at the end of the period differs from the price expected by investors based on the information available $\Phi_{t}$. As a result, in an efficient market it must be true that: 


$$
E\left(x_{j, t+1} \mid \Phi_{t}\right)=0
$$

This implies that the information is always impounded in stock prices. Therefore the rational expectations of the returns for a particular stock according to the EMH may be represented as:

$$
P_{t+1}=E_{t} P_{t+1}+\varepsilon_{t+1}
$$

Where $P_{t}$ is the stock price; and $\varepsilon_{t+1}$ is the forecast error. $P_{t+1}-E_{t} P_{t+1}$ should therefore be zero on average and should be uncorrelated with any information $\Phi_{t}$. Also $E\left(x_{j, t+1} \mid \Phi_{t}\right)=0$ when the random variable (good or bad news), the expected value of the forecast error, is zero:

$$
E_{t} \varepsilon_{t+1}=E_{t}\left(P_{t+1}-E_{t} P_{t+1}\right)=E_{t} P_{t+1}-E_{t} P_{t+1}=0
$$

Underlying the efficiency market hypothesis, it is opportune to mention that expected stock returns are entirely consistent with randomness in security returns. This position is supported by the law of iterated expectations (Campbell et al. 1997[23]; Samuelson 1965[8]). The expectational difference equation can be solved forward by repeatedly substituting out future prices and using the law of iterated expectations:

$$
\mathrm{E}_{\mathrm{t}}\left[\mathrm{E}_{\mathrm{t}}+\mathrm{I}_{\mathrm{t}}(\mathrm{X})\right]=\mathrm{E}_{\mathrm{t}}(\mathrm{X})
$$

Campbell et al. (1997[23]) state that:

...if one has limited information $\mathrm{I}_{\mathrm{t}}$, the best forecast one can make a random variable $\mathrm{X}$ is the forecast of the forecast one would make of $\mathrm{X}$ if one had superior information $\mathrm{J}_{\mathrm{t}}$, rewritten as $\mathrm{E}_{\mathrm{t}}\left[\mathrm{X}-\mathrm{E}\left[\mathrm{X} \mid \mathrm{J}_{\mathrm{t}}\right] \mid \mathrm{I}_{\mathrm{t}}\right.$ is equal to zero. One cannot use limited information $\mathrm{I}_{t}$ to predict the forecast error one would make if one had superior information $\mathrm{J}_{\mathrm{t}}$ (1997, p. 23)

Non-parametric testing of market efficiency is based on the premise of no arbitrage opportunities, i.e., those opportunities for earning unusual returns do not exist (Fama 1970[21]; Jensen 1978[22]). Along with other empirical studies (Ball 1978[24]; Charest 1978[25]; Banz 1981[26]; Schwert 1983[27]; Fama and French 1989[13]; Fama 1991[28]; Famaet al. 1993[29]; Lo 1996)[30], many researchers have also jointly tested the market efficiency with an asset pricing model. If the null hypothesis is rejected, the failure of either market efficiency or the model does exist. However, the authors have often preferred to conclude that difficulties in asset pricing theory, rather than market efficiency, underlie the rejection of the null hypotheses which have been uncovered in tests of asset pricing. In addition, the rejection of the null hypotheses is likely to have resulted from the misspecification of the asset pricing theory and not market efficiency itself.

\subsection{Random Walk Model}

Traditionally, lower the market efficiency, the greater the predictability of stock price changes. According to Fama (1970)[21], the efficient market exists if the share prices are reflected by the all available information. In other words, in an efficient market, price changes must be a response only to new information. As the information arrives randomly in market, the share prices fluctuate unpredictably. In weak-form efficient, the price movements fluctuate and the changes of price are independent. In that case, the investors cannot predict the insights of the future prices based on the past information and cannot earn abnormal returns.

The random walk idea of the asset price was introduced by Bachelier in 1900 (Poshakwale 1996)[31]. The random walk model sates that the price changes cannot be predicted from earlier changes, the successive price changes of any stock are independent and the price changes occur without any significant trends. The random walk will be consistent with equity being appropriately priced at an equilibrium level, whereas the absence of a random walk will follow the inappropriate of pricing of capital and risk. This has important implications for the allocation of capital development of overall economy.

\subsection{Empirical Evidence of Emerging Markets}

In recent, the emerging stock markets have been highly focused by both researchers and investors. Due to the globalization and investors' interest both local and international, the inflow of FDI, the emerging markets have opened up their economy which attracted to the global investors. Therefore, various studies have concentrated on the return behavior and the predictability to establish investors' confidence, but the majority of them examine the random walk behavior in emerging markets.

Laurence (1986)[32] studied on the KLSE stock exchange in Malaysia and SES stock exchange in Singapore to find out the random walk hypothesis for the period 1973 to 1978. Using the runs and autocorrelation test, he concluded that both KLSE and SSE did not follow the random walk and they are not weak form efficient. In contrast to Laurence (1986)[32] study, Barnes (1986)[33] found that the KLSE stock markets were weak form efficient for sample period 1975 to 1980. He used the same test of Laurence (1986)[32] and implied to 30 companies and sis sector indices.

On the other hand, Parkinson (1987)[34] tested the weak-form efficiency in Kenya (NSE) from 1974 to 1978 based on the monthly prices of 50 individual companies. He used the single run test only. The result showed that the NSE did not exhibit the weak-form efficiency. On the continuation of Parkinson (1987)[34] work, Dickinson and Muragu (1994)[35] also investigated NSE for the period 1979 to 1989 using the weekly prices of 30 most actively traded stocks. They revealed that the weak-form efficiency exist in NSE. So, the result is contradictory to the earlier study in Kenya. The reason might be the use of different test.

Gilmore and McManus (2003)[36] examined the random walk hypothesis in Czech Republic, Hungary and Poland for the period 1995 to 2000 based on the weekly comprehensive indices. They used the various methods including unit root, variance ratio, autocorrelation, Johansen and Granger 
causality, Naïve, ARIMA and GARCH. The result was mixed: All the tests except Granger-causality shoed the evidence against weak-form efficiency in Czech Republic, Hungary and Poland.

Abrosimova et al. (2005)[37] investigated the random walk hypothesis in Russian stock market using daily, weekly, monthly RTS indices from 1995 to 2001 and concluded that Russian market was weak form efficient. On the other hand, Hassan et al. (2006)[38] found that Czech Republic, Hungary, Poland and Russia were not weak form efficient, but Greece, Slovakia, and Turkey followed the random walks.

In a recent study, Siddiqui and Gupta (2009)[39] investigated the random walk hypothesis in the Indian stock market using daily stock indices from 1 January 2000 to 31 October 2008. They employed both non-parametric (Kolmogrov -Smirnov normality test and run test) test and parametric test (Auto-correlation test, Auto-regression, ARIMA model). They found that the Indian stock market did not follow weak form of market efficiency. They also mentioned that various macro-economic factors were important to justify the efficiency or inefficiency in emerging markets in recent times.

There are some studies conducted on the DSE for weak form efficiency but not on the CSE (Chittagong Stock Exchange). The first attempt was done by Alam et al. (1999)[40]. They examined the weak form efficiency of DSE for the period 1986 to 1995 based on the monthly stock price indices. Applying variance ratio test, they revealed that the DSE followed random walk model and the DSE was weak form efficient.

\subsection{EMH and Time Series Behavior}

Broadly speaking, the incident of white noise, random walk, martingale and fair game properties of financial time series is evidence in favor of EMH. To reiterate, the absence of arbitrage opportunities expresses the idea that the only chance for speculators to gain an opportunity to earn abnormal profits occurs if mispriced stocks exist in an economy populated by rational agents. In fact, the mispriced stocks will be automatically adjusted.

Since this scenario will be replayed every time an arbitrage opportunity arises, price levels will be continuously maintained according to the Samuelson's fair game theory or martingale difference. Samuelson (1965)[8]modeled this property of prices as the random walk:

$$
Y_{t}=Y_{t-1}+\varepsilon_{t}
$$

and random walk with drift (time trend):

$$
Y_{t}=\mu+Y_{t-1}+\varepsilon_{t}
$$

Random walks also exhibit Markov and martingale properties. A Markov property is the information for determining the probability of a future value of the random variable already contained or expressed in the current status of that variable. The martingale property is the conditional expectation of a future value of the random variable. The positive drift (called sub-martingale) in random walk exists when $\alpha$ is greater than zero. On the other hand, negative drift (called super-martingale) in random walk exists when $\alpha$ is less than zero. However, if $\alpha$ is equal to zero, then it would be a normal random walk. The martingale property is defined as:

$$
Y_{t}=Y_{t-1}+\alpha+\varepsilon_{t}
$$

Campbell et al. (1997, p. 29)[41] summarize the classification of random walk as in Table 1 .

Table 1. Classification of Random Walk model

$\begin{array}{ccc}\operatorname{Cov}\left[f\left(r_{t}\right), g\left(r_{t+k}\right)\right]= & g\left(r_{t+k}\right), \forall g(.) & g\left(r_{t+k}\right), \forall g(.) \\ & \text { Linear } & \\ \text { Uncorrelated } & \\ \text { Increments, } & \\ & \text { Random Walk 3: } & \\ & \text { Pr } o j\left[r_{t+k} \mid r_{t}\right]= & \\ & \text { Martingale/Fair } & \text { Independent Increments, } \\ f\left(r_{t}\right), \forall f(.) & \text { Game: } & \text { Random Walks 1 and 2: } \\ & E\left[r_{t+k} \mid r_{t}\right]=\mu & p d f\left[r_{t+k} \mid r_{t}\right]=p d f\left(r_{t+}\right.\end{array}$

Source: Campbell et al. 1997[41], p. 29.

Generally, if stock prices and returns are not predictable then these time series have the properties of martingale, fair game, random walk and white noise implying the validity of EMH. Since the existing empirical tests such as Islam and Watanapalachaikul (2005)[42] show the possibility of predictability of stock prices and returns, it can be argued that the stock prices and returns time series in DSE during the study period did not show those properties of time series - evidence against EMH.

\section{Research Question}

This study seeks the evidence whether the Dhaka Stock Exchange is weak form efficient or not and does it follow the random walk model?

The specific objectives of the present study linkage with the research questions are as follows:

a) To determine whether the Dhaka stock exchange follows a random walk model or is weak-form efficient.

b) To determine whether the Dhaka stock exchange is weak-form efficient.

\section{Hypotheses}

H1: The Dhaka stock market follows random -walk model. H2: The Dhaka stock market is efficient in weak form.

\section{Sample Period}

The sample included total 2682 daily observations for the total sample period 2001 to 2013. Toconfirm the results of 
the empirical analysis, we also computed the first sub-sample (November 2001-2007,first 6 years), the second sub-sample (2008-july 2013, last 6 years) and with observations excludingthe outliers.

\subsection{Sample Size}

The sample included total 2924 daily observations of daily price indices of DSE General Index (DGEN) for the periodfrom2001 to 2013.

\section{Non-parametric Stock Market Efficiency Tests}

There are a large number of other direct tests of EMH. In addition, indirect tests are also used as evidence for or against the EMH.

Keane, S. (1983, p. 31)[43] provides some basic explanations of what makes markets inefficient. One of his ideas is called "Gambler's Fallacy". This may be described as the belief that what "goes up must come down". This phenomenon exhibits itself amongst investors whose stocks' price has risen for a period of time and so is deemed to be "due for a fall". Generally speaking, by knowing the relationship of the current price to recent price movements, one can better estimate the likely direction of future price movements, i.e. historical data such as price movement can be used to predict future prices. This provides credibility to the argument that the market is predictable and inefficient. Therefore, the issue is to see whether the stock market is predictable or not by detecting serial dependence of stock returns. In this paper, we applied the popular tests of market efficiency which can test serial dependence of stock returns are functional, which is ACF test.

The results of the test will be supplemented by the evidence from tests of predictability, anomaly, and volatility reported by the authors in Islam and Watanapalachaikul (2005)[42], to draw a conclusion about EMH in the DSE. It should be noted that Alom and Raquib (2014)[44] has already tested EMH of DSE, though with different variables.

\section{Methodology}

This paper has been designed using autocorrelation function test and subsequently to cross-validate findings we have gone through another two tests- that is on one-sample t-test and one-sample Kolmogorov-Smirnov Test. In addition to that, descriptive statistics of the index have been shown. The ACF test is examined to identify the degree of autocorrelation in a time series. It measures the correlation between the current and lagged observations of the time series of stock returns, which is defined as:

$$
p_{k}=\frac{\sum_{t=1}^{n-k}\left(R_{t}-\bar{R}\right)\left(R_{t+k}-\bar{R}\right)}{\sum_{t=1}^{n}\left(R_{t}-\bar{R}\right)^{2}}
$$

where $k$ is the number of lags, and $R_{t}$ represents the real rate of return calculated as:

$$
R_{t}=\ln \left(\frac{I_{t}}{I_{t-1}}\right) \times 100=\alpha+u
$$

Two important elements for estimating of autocorrelation are the standard error test and the Box Pierce Q (BPQ) test. The standard error test measures the autocorrelation coefficient for individual lags and identifies the significant one, whiles the Box Pierce Q test, measures the significant autocorrelation coefficients at the group level.

The standard error $\sigma_{k}$ is defined as:

$$
\sqrt{\frac{1+2 \sum_{t=1}^{k-1} \theta_{t}^{2}}{N}}
$$

Where $\mathrm{N}$ is the total number of observations and $\theta_{k}$ is the autocorrelation at lag $(k)$.

Box Pierce $\mathrm{Q}$ is identified as:

$$
N(N+2) \sum_{t=1}^{k} \frac{R_{t}^{2}}{N-t}
$$

We used daily index (DGEN) of the market return to calculate ACF.

\section{Results}

Descriptive statistics in Table 2 shows that data are normally distributed with a mean value of 2810.73 and standard deviation of 1.93 which implies normal distribution of the data.

Table 2. Descriptive Statistics

\begin{tabular}{|c|c|c|c|c|c|c|c|c|c|}
\hline & $\mathrm{N}$ & Maximum & Mean & $\begin{array}{c}\text { Std. } \\
\text { Deviation }\end{array}$ & Variance & \multicolumn{2}{|c|}{ Skewness } & \multicolumn{2}{c|}{ Kurtosis } \\
\hline & Statistic & Statistic & Statistic & Statistic & Statistic & Statistic & Std. Error & Statistic & Std. Error \\
\hline $\begin{array}{c}\text { DSE GENERAL } \\
\text { INDEX (DGEN) }\end{array}$ & 2927 & 8918.5135 & 2810.734078 & $1.9355256 \mathrm{E} 3$ & 3746259.317 & .898 & .045 & -.151 & .090 \\
\hline Valid N (list-wise) & 2927 & & & & & & & & \\
\hline
\end{tabular}


Table 3 shows the autocorrelation from the year 2001-2013 and periodical correlation from the year 2001 to 2013 as well 2001 to 2007 and 2008 to 2013 period of the stock market return (DSE) in the ACF test.

Table 3. Autocorrelation of the DSE returns 1998-2009.

\begin{tabular}{|c|c|}
\hline Year & Autocorrelation \\
\hline $2001-2013$ & 0.0243 \\
\hline 2001-2007 & 0.0944 \\
\hline $2008-2013$ & 0.0217 \\
\hline 2001 & 0.0792 \\
\hline 2002 & 0.1458 \\
\hline 2003 & 0.2531 \\
\hline 2004 & 0.1005 \\
\hline 2005 & 0.0852 \\
\hline 2006 & 0.1678 \\
\hline 2007 & 0.0173 \\
\hline 2008 & 0.0597 \\
\hline 2009 & 0.0295 \\
\hline 2010 & -0.0039 \\
\hline 2011 & 0.0276 \\
\hline 2012 & -0.0313 \\
\hline 2013 & -0.0214 \\
\hline \multicolumn{2}{|c|}{$\begin{array}{c}\mathrm{N}=2924 \\
\mathrm{~K}=1\end{array}$} \\
\hline
\end{tabular}

According to the results, we found that in our observed period from 2001 to 2013 in DSE weak form of efficiency doesn't exist. There are movements of autocorrelation at various lags that hover around positive numbers. This explains the non-stationary time series. The results exhibit a small level of positive autocorrelation of the periodic returns on the DSE during 2001-2013. The ACF tests of yearly return are similar in that both tests produce a positive and negative autocorrelation. So, Autocorrelation test rejected of both hypotheses that is DSE doesn't follow random walk model and it doesn't hold any weak form of efficiency. So, anyone can make abnormal profit using the past information, basically that is not the characteristics of weak form of efficient markets that follow a random walk model.

Correlogram:

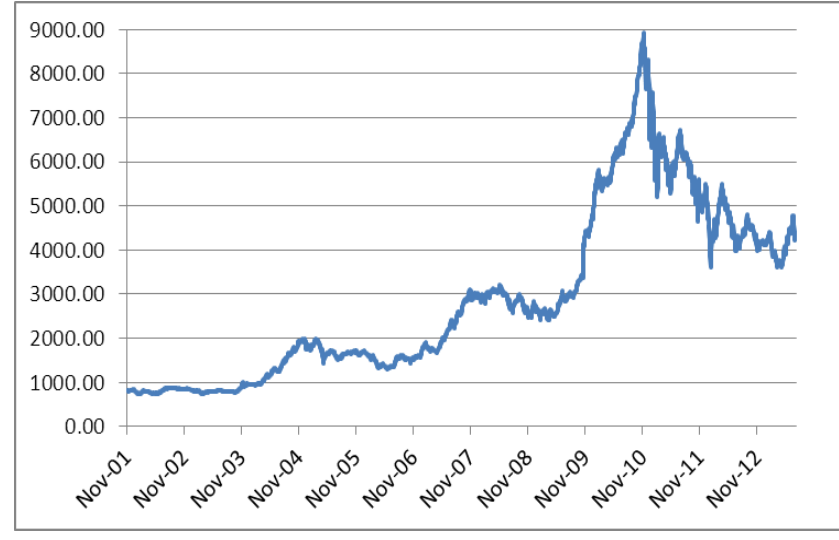

Figure 1. Correlogram of the autocorrelation function on stock returns, 2001-2013

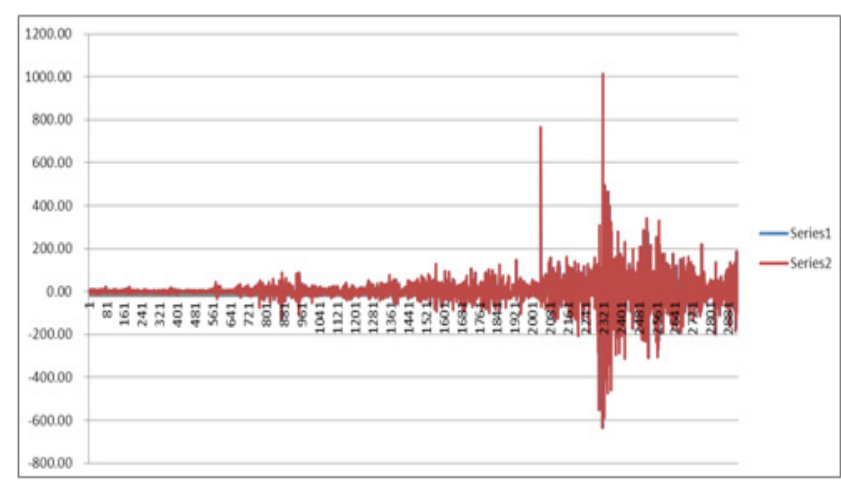

Figure 2. Correlogram of the partial autocorrelation function on stock returns, 2001-2013

To see if ACF is significant, the study period from 2001-2013, correlation of the market return is 0.0243 , which is a positive figure and Therefore, we can reject the hypothesis ( $\mathrm{H} \mathrm{1}$ ), the rejection of $\mathrm{H} 1$ will automatically reject the $\mathrm{H} 2$ of the presence of autocorrelation from the period 2001 to 2013.

From Table 4, it can be seen that the $t$ value is .948, which indicates one sample $t$ test is significant and price change has positive relation from earlier day price. This findings support the existing result we got from autocorrelation test.

This test also supports the existing findings from above two tests. It's a two tail test and shows that in most extreme differences the DGEN index demonstrates positive and negative relation that implies positive relationship among the price changes. It means DSE is following a price trend and relationship is found, which rejected the null that DSE is not weak form efficient.

Table 4. One-Sample Statistics

\begin{tabular}{|c|c|c|c|c|c|c|}
\hline & & & & $e=0$ & & \\
\hline & $\mathrm{t}$ & df & Sig. (2-tailed) & Mean Difference & $\begin{array}{r}95 \% \mathrm{C} \\
\text { Interv } \\
\text { Diff } \\
\end{array}$ & $\begin{array}{l}\text { lence } \\
\text { the } \\
\text { ce }\end{array}$ \\
\hline \multirow{2}{*}{ Pricechange } & \multirow{2}{*}{.948} & \multirow{2}{*}{2925} & \multirow{2}{*}{.343} & \multirow{2}{*}{1.20716} & Lower & Upper \\
\hline & & & & & -1.2900 & 3.7044 \\
\hline
\end{tabular}


Table 5. One-Sample Kolmogorov-Smirnov Test

\begin{tabular}{|c|c|c|}
\hline \multicolumn{2}{|c|}{$\mathrm{N}$} & Pricechange \\
\hline \multirow{2}{*}{$\begin{array}{c}\text { Normal Parameters } \\
\text { a,b }\end{array}$} & Mean & 2926 \\
\cline { 2 - 3 } & Std. Deviation & 1.2072 \\
\hline $\begin{array}{c}\text { Most Extreme } \\
\text { Differences }\end{array}$ & Absolute & 68.89101 \\
\hline & Positive & .197 \\
\cline { 2 - 3 } & Negative & .183 \\
\hline \multicolumn{2}{|c|}{ Kolmogorov-Smirnov Z } & -.197 \\
\hline \multicolumn{2}{|c|}{ Asymp. Sig. (2-tailed) } & 10.656 \\
\hline
\end{tabular}

a. Test distribution is Normal.

b. Calculated from data.

\section{Conclusions}

The theoretical and empirical studies of the efficient market hypothesis have made an important contribution to the understanding of the stock market, although the present state of understanding of the issue, especially in the emerging financial markets, is far from being decisive. The results of the present study show that there is a positive autocorrelation on stock market returns in DSE during the period of 2001-2013 that is 0.0243. The result from the autocorrelation test rejects the both hypotheses. From this we may conclude that these emerging stock markets are not weak form efficient. To check the robustness of the test we did auto-correlation for two sub-samples (2001-2007 and 2008-2013) and also graphically analyzed the partial auto-correlation. The results for both were similar and supported our previous findings.

The inefficiency of Dhaka Stock Exchange follows from the violation of the necessary conditions for an efficient market with a developed financial system and also implies financial and institutional imperfections. This leads to the conclusion that Bangladesh financial policies and regulations such as those concerning liberalization, deregulation and insincerity of Securities and Exchange Commission (SEC) have generated a perceived inconsistency, and a tendency to produce instability. The implication is that the benefits of a well-functioning stock market are not being realized in the economy. Indeed, the weak-form inefficiency of the stock market demonstrated in this study is most likely caused by a combination of the lack of its development and the implication of policy choices and the proper functioning watchdog. It is necessary to gain more insights into the operation and characteristics of the stock market in Bangladesh (DSE) of its efficiency and the valuation processes to make an informed assessment of the empirical characteristics of the Bangladesh financial market. It needs to be mentioned that

\section{Limitations and Future Research}

This study initiates a number of limitations and potential fruitful paths for future research. We did not cross validate the other emerging market comparing the study period of DSE when we considered results of the latest research. In this research we conducted only the autocorrelation function test (ACF) and concluded our findings based on that result but other popular non parametric test could be conducted in this research. Our sample period was for the 12 years from 2001-2013, more specifically from November 27, 2001 to July 31, 2013 for the period during which DSE produced and published the DSE General Index (DGEN); this index was, however, discontinued after this date. Due to budget and time constrain, research based on data for a longer period, that is based on DSE All Share Price Index (DSI) could not be done. Future research should include those prescribed factors other than considered in this study.

This study does not cover in depth psychological dimension of the investors. This study also does not cover external environmental factors such as market anomaly, event etc. which may have effect on the return of the market.

In conclusion, future study should focus on which factors have focused in the prior discussion and helps to make a justified concluding remark about the emerging as well Dhaka Stock Exchange.

\section{REFERENCES}

[1] Islam S and Oh KB (2003) Applied financial econometrics in e-commerce. Contributions to Economic Analysis, North Holland Publishing, Amsterdam.

[2] Mills TC (1999) The econometric modelling of financial time series. Cambridge University Press, Cambridge.

[3] Cuthbertson K (1996) Quantitative financial economics: stocks, bonds, foreign exchange. John Wiley and Sons, London.

[4] Bollerslev T and Hodrick RJ (1999) Financial Market Efficiency Tests (in Pesaran MH and Wickens MR (1999) Handbook of Applied Econometrics, Volume I: Macroeconomics. Blackwell Publishers, Oxford).

[5] Pesaran MH and Wickens MR (1999) Handbook of Applied Econometrics, Volume I: Macroeconomics. Blackwell Publishers, Oxford

[6] Fama EF (1976) Foundations of finance.Basic Books, New York.

[7] Fama EF (1965) "The behaviour of stock market prices".Journal of Business. 38:34-105.

[8] Samuelson PA (1965) "Proof that properly anticipated prices fluctuate randomly". Industrial Management Review. 6:4150.

[9] Sharpe WF (1966) "Mutual fund performance". Journal of Business.January.

[10] Friend I, Blume M and Crockett J (1970) Mutual funds and other institutional investors: a new perspective. McGraw-Hill, New York. 
[11] Williamson J (1972) "Measuring mutual fund performance". Financial Analysts Journal.November/December.

[12] Campbell JY and Shiller RJ (1987) "Cointegration and tests of present value models". Journal of Political Economy. 95:1062-1088.

[13] Fama EF and French KR (1989) "Business conditions and expected returns to stocks and bonds". Journal of Financial Economics. 25:23-50.

[14] Harvey CR (1991) "The world price of covariance risk". Journal of Finance. 46:111-157.

[15] Jensen M and Ruback RS (1983) "The market for corporate control: the scientific evidence". Journal of Financial Economics. 11:5-50.

[16] McConnell JJ and Muscarella CJ (1985) "Corporate capital expenditure decisions and the market value of the firm". Journal of Financial Economics. 14:399-422.

[17] Kettel B (2001) Financial economics: making sense of market information. Financial Times Prentice Hall, London

[18] Alam, I. M., Hasan, T. and Kadapakkam, P. (1999). An Application of Variance-Ratio Test to Five Asian Stock Markets.Review of Pacific Basin Financial Markets and Policies 2, pp. 301-315.

[19] Hassan, M. K., Islam, A. M. and Basher, S. A. (2000). Market Efficiency, Time-VaryingVolatility and Equity Returns in Bangladesh Stock Market. Available at: http://econwpa.wustl.edu:80/eps/fin/papers/0310/0310015.pd f. Accessed: $17 \quad$ February 2009.http://www.fgda.org/pubblicazioni_schedarivistauk.ph p?Id=780. Accessed: 27 January 2009 .

[20] Mobarek, A. and Keasey, K. (2002). Weak-Form Market Efficiency of an Emerging Market: Evidence from Dhaka Stock Market of Bangladesh. (http://www.bath. ac.uk/Centres/CDS/enbs-papers/mobarek_new.htm, Accessed: 12 February 2009).

[21] Fama EF (1970) "Efficient capital markets: a review of theory and empirical work". Journal of Finance. 25:383-417.

[22] Jensen M (1978) "Some anomalous evidence regarding market efficiency". Journal of Financial Economics. 12:3356.

[23] Campbell JY, Lo AW and MacKinlay AC (1997) The econometrics of financial markets. Princeton University Press, New Jersey.

[24] Ball R (1978) "Anomalies in relationships between securities yields and yield-surrogates". Journal of Financial Economics. 6:103-126.

[25] Charest G (1978) "Split information, stock returns and market efficiency”. Journal of Financial Economics. 6:265-330.

[26] Banz RW (1981) "The relationship between return and market value of common stocks". Journal of Financial Economics. 9:3-18.

[27] Schwert GW (1983) "Size and stock returns, other empirical regularities". Journal of Financial Economics. 12:3-12.

[28] Fama EF (1991) "Efficient capital markets: II”. Journal of Finance.96:1575-1617.
[29] Fama EF, French K, Booth D and Sinquefield R (1993) "Differences in the risks and returns of NYSE and NASD stocks". Financial Analysts Journal. 49:37-41.

[30] Lo A (1996) Market efficiency: stock market behaviour in theory and practice. Edward Elgar Publishing, London.

[31] Poshakwale, S. (1996) "Evidence on Market efficiency and Day-of-the-week Effect in the Indian Stock Market",FinanceIndia,Vol.X, No.3, 605-616

[32] Laurence, M. (1986) "Weak-form efficiency in the Kuala Lumpur and Singapore stock markets", Journal of Banking and Finance, 10,431-445.

[33] Barnes, P. (1986) "Thin trading and stockmarket efficiency: the case of the KualaLumpur Stock Exchange.Journal of Banking Finance and Accounting", 13,609-617. Reprinted in I. Ibrahim and O. Yong (eds.) "Understanding thebehavioural patterns of stock prices: acollection of readingson selected fareastern stock markets", pp.65-72. Kuala Lumpur: Leeds Publications.

[34] Parkinson, J.M. (1987) "The EMH and the CAPM on the Nairobi Stock Exchange", East African Economic Review, 3 (2): $105-110$

[35] Dickinson, J.P. and Muragu, K. (1994) "Market Efficiency in Developing Countries: A Case Study of the Nairobi Stock Exchange". Journal of Business Finance and Accounting, 21 (1):133-150.

[36] Gilmore, C.G., and G.M. McManus,2003."Bilateral and Multilateral Cointegration Properties between the German and Central European Equity Markets." Studies in Economics and Finance 21:40-53.

[37] Abrosimova, N., Dissanaike, G., Linowski, D. (2005) "Testing the weak from Efficiency of the Russian Stock Market".

https://papers.ssrn.com/sol3/papers.cfm?abstract_id=302287.

[38] Hassan, K. M., Haque, M., and Lawrence, S. (2006):“An Empirical Analysis of Emerging Stock Markets of Europe". Quarterly Journal of Business and Economics, vol. 45, no. 1 \& 2, 31-52.

[39] Siddiqui,S\&Gupta,P.K.(2009), “An Appraisal of Life Insurance Sector under IRDA, JIM Quest, 5:1-7. (ISSN:0975-6280)

[40] Alam MI, Hasan T, Kadapakkam P (1999). “An Application of Variance Ratio Test to Five Asian Stock Markets", Rev. Pac. Basin Financ. Mark. Pol.,2: 301-315

[41] Campbell JY, Lo AW and MacKinlay AC (1997) "The econometrics of financial markets" Princeton University Press, New Jersey.

[42] Islam S and Watanapalachaikul S (2005) "Empirical finance: modelling and analysis of emerging financial and stock market", Springer-Verlag, Heidelberg.

[43] Keane, S. (1983) "Stock market efficiency", Phillip Allan Publishers, Oxford.

[44] Alom, K. and Raquib, M. (2014) "Capital Market Efficiency and Portfolio Equity Inflows in Bangladesh", World Vision Research Journal, Vol. 8, Issue 1/2013, pp. 202-215 